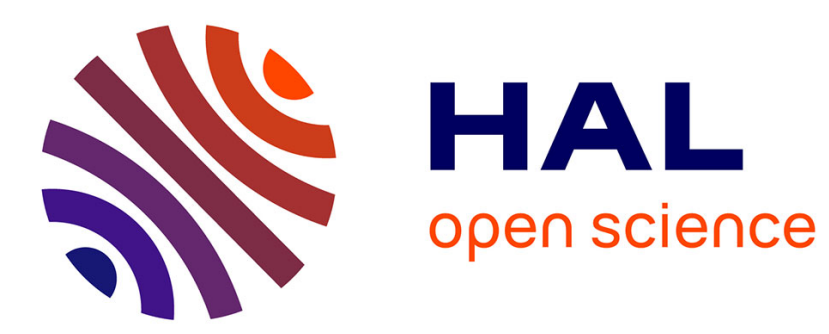

\title{
Impact of tracheostomy on swallowing performance in Duchenne muscular dystrophy.
}

Nicolas Terzi, Hélène Prigent, Michèle Lejaille, Line Falaize, Djillali Annane, David Orlikowski, Frédéric Lofaso

\section{- To cite this version:}

Nicolas Terzi, Hélène Prigent, Michèle Lejaille, Line Falaize, Djillali Annane, et al.. Impact of tracheostomy on swallowing performance in Duchenne muscular dystrophy.: Swallowing and Tracheostomy in DMD. Neuromuscul Disord, 2010, 20 (8), pp.493-8. 10.1016/j.nmd.2010.05.009 . inserm-00516703

\section{HAL Id: inserm-00516703 https://www.hal.inserm.fr/inserm-00516703}

Submitted on 10 Sep 2010

HAL is a multi-disciplinary open access archive for the deposit and dissemination of scientific research documents, whether they are published or not. The documents may come from teaching and research institutions in France or abroad, or from public or private research centers.
L'archive ouverte pluridisciplinaire HAL, est destinée au dépôt et à la diffusion de documents scientifiques de niveau recherche, publiés ou non, émanant des établissements d'enseignement et de recherche français ou étrangers, des laboratoires publics ou privés. 


\section{Impact of Tracheostomy on Swallowing Performance in Duchenne Muscular Dystrophy}

Nicolas TERZI ${ }^{1}$, Hélène PRIGENT ${ }^{2}$, Michèle LEJAILLE ${ }^{2}$, Line FALAIZE $^{2}$, Djillali ANNANE ${ }^{2}$, David ORLIKOWSKI ${ }^{2}$, and Frédéric LOFASO ${ }^{2,3}$

${ }^{1}$ Service de Réanimation Médicale, CHU de Caen, 14000 Caen, France

${ }^{2}$ Services de Physiologie - Explorations Fonctionnelles, Réanimation Médicale, et Centre d'Investigation Clinique - Innovations Technologiques, Hôpital Raymond Poincaré, AP-HP ; E.A. 4497, Université de Versailles-Saint Quentin en Yvelines, 92380 Garches, France ${ }^{3}$ Inserm U 955, 94000 Créteil, France

Correspondence: Nicolas TERZI MD, Service de Réanimation Médicale, CHU de CAEN, 14000 CAEN, France

Tel.: +33 231064 716; Fax: +33 231064996 ; E-mail: terzi-n@ chu-caen.fr

Running title: Swallowing and Tracheostomy in DMD

Word count (body of manuscript): 2549 


\begin{abstract}
Mechanical ventilation has improved survival in patients with Duchenne muscular dystrophy (DMD). Over time, these patients experience upper airway dysfunction, swallowing impairments, and dependency on the ventilator that may require invasive mechanical ventilation via a tracheostomy. Tracheostomy is traditionally believed to further impair swallowing. To evaluate the effect of tracheostomy on swallowing we assessed swallowing performance and breathing-swallowing interactions before and after tracheostomy in 7

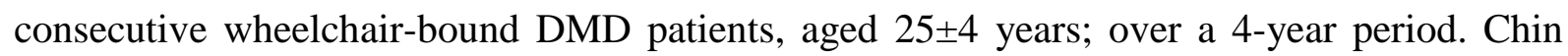
electromyography, laryngeal motion, and inductive respiratory plethysmography recordings were obtained during swallowing of three water-bolus sizes in random order. The evaluations were done before and after tracheostomy. Piecemeal deglutition occurred in all patients over several breathing cycles. Half the swallows were followed by inspiration before tracheostomy. Total bolus swallowing time was significantly shorter $(P=0.009)$ and the number of swallows per bolus significantly smaller $(P=0.01)$ after than before tracheostomy. Invasive ventilation via a tracheostomy may improve swallowing.
\end{abstract}

Abstract word count: 153 pour un maximum de 150

Keywords: Neuromuscular disorder, swallowing, tracheostomy, invasive mechanical ventilation. 


\section{INTRODUCTION}

The introduction of mechanical ventilation (MV) has improved survival in patients with Duchenne muscular dystrophy (DMD) from about 15 years in the 1960s to more than 30 years now [1-4]. However, the patients experience increasing physical disability and dependence on care with advancing age [3].

Invasive or noninvasive mechanical ventilation can be used for long-term ventilatory assistance [5, 6]. Noninvasive ventilation (NIV) is initially offered at night to treat sleeprelated breathing disorders and hypoventilation, which are common in patients with DMD [7]. As the disease progresses, hypoventilation starts to occur during the day, requiring daytime ventilatory assistance, generally as intermittent positive-pressure ventilation via a mouthpiece or nasal mask [8]. Dependence on the ventilator increases over time, and many patients become unable to use a mouthpiece and to tolerate prolonged nasal ventilation during the day. Eventually, severe upper airway dysfunction develops, impairing NIV efficiency. At this stage, tracheostomy may be considered $[6,8]$.

The severe upper airway dysfunction seen in DMD is often associated with swallowing difficulties. These difficulties affect $18 \%$ of patients above the age of 18 years and increase with advancing age [9]. Other factors contribute to cause feeding difficulties, including weakness of the masticatory muscles, malocclusion, and inability to self-feed [9]. The feeding difficulties often develop insidiously, being frequently missed by family members and healthcare professionals, [10] and may lead to inadequate food intake. Thus, malnutrition develops in up to $44 \%$ of DMD patients $[8,11]$. Aspiration is another severe consequence of impaired swallowing that becomes increasingly common as the disease progresses [8]. The ATS recommends gastrostomy tube placement when adequate nutrition cannot be safely achieved via oral feeding [8]. However, we have noted that some patients who underwent gastrostomy before tracheostomy became capable of oral feeding during 
invasive mechanical ventilation via the tracheostomy. This observation suggests that a tracheotomy may provide improvements in quality of life by obviating the need for gastrostomy.

The objective of this study was to assess the impact of tracheostomy combined with positive pressure ventilation on breathing/swallowing interactions and swallowing performance in DMD patients in whom permanent NIV was either not sufficiently effective or not well tolerated.

\section{METHODS}

\section{Study population}

We conducted a prospective observational study from February 2006 to February 2009. The relevant ethics committee (Hôpital A. Paré, Paris, France) approved the study and written informed consent was obtained from all patients before study inclusion.

Patients with DMD were recruited during routine follow-up visits at ventilatory unit if they had been in stable clinical condition for at least the past month, were receiving NIV, and had consented to undergo tracheostomy. Tracheostomy was decided because NIV was inadequately effective or poorly tolerated. Informed consent for tracheostomy was obtained after a detailed discussion of social factors and living arrangements [6].

\section{Study procedures}

Thoracic and abdominal movements were monitored using respiratory inductive plethysmography. Swallowing was monitored noninvasively, using electromyography to detect submental muscle activity via skin-surface electrodes on the chin and a piezoelectric sensor placed between the cricoid and thyroid cartilages, as described elsewhere [12-14]. All signals were digitized and recorded directly on a personal computer. 


\section{Experimental protocol}

The patient was seated comfortably with the head and neck maintained in the preferred position. All patients were assessed just before tracheostomy and 3 months after tracheostomy. After tracheostomy, mechanical ventilation was used during the assessment [6]. Before tracheostomy, patients were allowed to choose whether to use NIV during the assessment, as no recommendations existed for this situation [15]. Water boluses were placed in the mouth using a syringe. Three bolus sizes were used, $(5,10$, and $15 \mathrm{ml})$, in random order. Patients were blinded to bolus size. As previously published (references) four sets of three boluses were studied, without using the same bolus size twice consecutively. Each bolus was separated by 2 minutes. Patients were asked to swallow normally and as efficiently as possible. The recording was checked and swallows were counted until the patient was able to open his mouth in order to demonstrate mouth emptying. Indeed, mouth was emptied between boluses. At completion of each measurement session, patients used the modified 10-point Borg scale to evaluate their worst sensation of respiratory difficulty during the session [16].

\section{Data analysis}

The investigator who read the recordings was blinded to the experimental condition. Blinding was maintained by analyzing swallowing independently from thoracic and abdominal movements. Swallowing onset was defined as the onset of phasic submental electromyographic activity and swallowing termination as the onset of downward laryngeal movement detected by the piezoelectric sensor $[12,14]$. For each bolus size, we recorded swallowing duration, number of swallows, and number of ventilatory cycles required to swallow the entire bolus. The percentages of swallows followed by expiration were computed. Indeed, swallowing in normal individuals is nearly always followed by expiration [17-19]. 


\section{Statistical analysis}

All results are reported as mean \pm standard deviation in the text and as mean \pm standard error of the mean in the figures. Statistical tests were run using the Stat View 5 package (SAS Institute, Grenoble, France).

We used two-way analysis of variance (ANOVA) for repeated measurements, with tracheostomy and bolus-size as the two factors. In patients who were unable to swallow the largest bolus, $[12,14]$ a paired $t$-test was used to compare results obtained with the smallest bolus. A paired $t$-test was also used to compare Borg scale results. $P$ values less than 0.05 were considered statistically significant.

\section{RESULTS}

\section{Study population}

We included 7 consecutive DMD patients. Table 1 reports their main anthropometric characteristics, and different respiratory parameters. All patients had a Hauser Ambulatory Index [20] of 9/9, indicating confinement to the wheelchair and inability to self-transfer. In addition, none of the patients was able to self-feed, however none of them needed a gastrostomy because all were used to swallow liquids and to eat, at least, blended food. The reason for tracheostomy was inadequate effectiveness of NIV in 1 patient (\#5) and poor tolerance of NIV during the long periods of use required in the other 6 patients. Duration of non invasive ventilation prior tracheostomy is $60 \pm 32$ months (Table1).

Assist-control mechanical ventilation was used, with an uncuffed tracheostomy tube after tracheostomy. Initially, tidal volume was set between 10 and $12 \mathrm{ml} / \mathrm{kg}$ and the backup respiratory rate was set two to three breaths per minute below the awake respiratory rate during spontaneous breathing, as recommended [21, 22]. Subsequently, tidal volume was adjusted to avoid hypercapnia. 


\section{Swallowing variables}

None of the patients chose to use NIV during testing before tracheostomy. All tests after tracheostomy were done with mechanical ventilation.

Piecemeal deglutition was noted in all patients, with each bolus often requiring several swallows over several breathing cycles. Before tracheostomy, 2 patients (\#1 and 3) were unable to swallow $15 \mathrm{ml}$ and one (\#1) to swallow $10 \mathrm{ml}$. All patients were able to swallow all bolus sizes after tracheostomy. In addition, for each patient and each bolus size that could be swallowed before tracheostomy, number of swallows and total bolus swallowing time were lower after tracheostomy. To perform the ANOVA on all patients including patients \#1 and \#3 who were unable to swallow the largest boluses, we replaced the missing data by the data obtained with the largest bolus size swallowed, which provided a conservative estimate of the tracheostomy effect. Nevertheless, total bolus swallowing time was significantly shorter and number of swallows per bolus significantly smaller after rather than before tracheostomy (ANOVA, $P=0.009$ and $P=0.01$, respectively; Figures $1 \mathrm{~A}, 1 \mathrm{~B}$ ). The number of breathing cycles needed for swallowing was smaller after tracheostomy, but the difference was not statistically significant (ANOVA, $P=0.06$ ).

All patients were able to swallow the smallest bolus $(5 \mathrm{ml})$ both before and after tracheostomy. For this bolus size, tracheostomy was followed by significant decreases in total swallowing time ( $t$-test, $P=0.013)$ and number of breathing cycles needed for swallowing $(t$ test: $P=0.03$ ). The number of swallows per bolus was smaller after tracheostomy, but the difference was not statistically significant ( $t$-test, $P=0.07$ ).

Individual results with the largest bolus $(15 \mathrm{ml})$ are reported in Figure 2. The increase in bolus size was associated with significant increases in total bolus swallowing time, number of swallows per bolus, and number of breathing cycles needed (ANOVA, $P=0.003, P<0.0001$, and $P=0.04$, respectively; see Figure 1). 
The Borg score at the end of each swallowing evaluation was significantly lower after tracheostomy $(0.4 \pm 0.8$ vs. $2.9 \pm 2.3 ;$-test, $P=0.02)$.

Table 1 reports the weight of each patient before and after tracheostomy.

\section{Coordination between swallowing and respiration}

The percentage of swallows followed by expiration was not significantly different before and after tracheostomy (ANOVA, $P=0.13$ ). With all three bolus sizes, nearly $50 \%$ of swallows were followed by inspiration.

\section{DISCUSSION}

Tracheostomy provides a secure interface for mechanical ventilation but is traditionally believed to impair swallowing $[6,8]$. However, we found that swallowing performance improved after tracheostomy combined with positive pressure ventilation in patients with advanced DMD. When tested during mechanical ventilation via a tracheostomy, our patients showed improvements in bolus size, swallowing time, and number of swallows per bolus. In addition, they reported less perceived respiratory difficulty during swallowing.

As expected, we found major swallowing impairments in our patients with advanced DMD, in accordance with our earlier study in patients with diverse neuromuscular diseases [12]. Thus, swallowing was fragmented, and about half the swallows were followed by an inspiration. All our study patients had severe generalized muscle weakness with hypoventilation in the absence of mechanical ventilation. Thus, the abnormal swallowingbreathing pattern found before tracheostomy might be related to a stronger respiratory drive in these patients with chronic respiratory failure, compared to healthy individuals. In keeping with this possibility, poor breathing-swallowing coordination was also found in patients with chronic obstructive pulmonary disease $[23,24]$ and was considered a risk factor for aspiration [25]. Hypercapnic neuromuscular patients usually exhibit rapid shallow breathing, [26] which 
may impair breathing/swallowing coordination. Furthermore, breathing/swallowing interactions are adversely affected by hypercapnia, abnormal elastic load, and small inspiratory volume, all of which were present in our population [25, 27, 28]. NIV improves these abnormalities, but as they usually eat without NIV, all the study patients chose to perform the pre-tracheostomy tests without NIV. On the other hand, in patients who breathe spontaneously while eating or drinking, competition between swallowing and breathing may lead to a large amount of pharyngeal residue and to choking episodes, which may in turn cause fear of swallowing. Mechanical ventilation via a tracheostomy may disrupt this vicious circle not only by correcting the hypercapnia, increasing the inspired volume, and decreasing the elastic work of breathing $[25,27]$, but also by eliminating the need to coordinate breathing and swallowing. The patient can concentrate fully on swallowing, which may explain the improved swallowing performance in our study.

In addition, by maintaining positive subglottic pressure throughout the ventilator cycle, invasive mechanical ventilation may protect against inhalation, whereas dyscoordination between swallowing and breathing observed before tracheostomy may increase the risk of inhalation. In healthy individuals, low or absent positive subglottic pressure during the swallow increased the swallowing time by prolonging the pharyngeal contraction [28]. This finding suggests that one component in the regulation of swallowing is stimulation of the subglottic mechanoreceptors, which is related in part to input from the respiratory system [28]. In accordance with this hypothesis, swallowing is impaired in patients who have an open tracheostomy tube, which causes leaks below the true vocal folds, thereby preventing subglottic pressurization [29]. Tracheal occlusion by a one-way speaking valve restored positive subglottic pressures during swallowing and improved swallowing and/or decreased aspiration in several studies [30-33], although another study found no effect on aspiration [34]. During the post-tracheostomy tests, our patients received positive pressure 
ventilation through an uncuffed tracheostomy tube, which maintained positive subglottic pressures throughout the ventilator cycle. This condition was associated with better swallowing performance in our DMD patients compared to pre-tracheostomy and compared to those seen in our earlier study with a one-way speaking valve in patients with a variety of neuromuscular disorders [12]. Finally, invasive mechanical ventilation via a tracheostomy increases the tidal volume which is known to improve swallowing performance [28].

\section{Methodological issues}

One limitation of our study is the small number of patients $(n=7)$. However, since the demonstration that NIV combined with other supportive measures prolongs the survival of DMD patients well into adulthood [3, 4], tracheostomy has been reserved for the small proportion of patients in whom NIV is inadequately effective or poorly tolerated. Thus, the 7 study patients were among $56(12.5 \%)$ nontracheostomized adult DMD patients who received follow-up at our unit between 2006 and 2008, in accordance with reports by other groups [3, 35]. During the same period, none of the 56 patients required tracheostomy for acute respiratory failure, indicating that our management strategy is effective in preventing this complication. Although our population was small, it was homogeneous in terms of the diagnosis, age, and respiratory function. Furthermore, tracheostomy combined with positive pressure ventilation was followed by improved swallowing performance in all the patients.

We used water for our swallowing assessments. There is some evidence that choking may occur only with solids in some DMD patients [9]. However, water rather than jelly was used in most of the previous studies, $[17,25,36,37]$ which allowed us to compare our results to earlier data. Furthermore, the use of solids requires chewing, which may cause fatigue and, therefore, worsen swallowing impairments. Nevertheless, it was not possible to evaluate solid 
food consistency considering that solid food was banned from the nutrition of most of our patients.

Our test protocol did not involve the detection of aspiration. Flexible endoscopic evaluation of pharyngeal function is considered as the gold standard in assessing pharyngeal propulsion and laryngeal stasis [38] (both of which mainly depend on muscle strength in DMD patients), and finally aspiration [38]. In this first study, we chose not to use this gold standard as it a relatively invasive technique which, in our experience, is less liable to allow a safe and calm exploration before tracheostomy in patients with a major breathing impairment; this might influence the objectivity and the evaluation duration between the two conditions. Furthermore, Flexible endoscopic evaluation could not detect differences in propulsion and laryngeal stasis because tracheostomy can only modify the swallowing/breathing competition but not the swallowing muscle strength consequences. Finally, the presence of a nasal and retropalatal foreign device may alter breathing conditions, before tracheostomy in this population unable to maintain adequate spontaneous breathing and which is known to frequently present a macroglossy. Therefore, the nasofibroscopy may influence the parameters tested before tracheostomy, but not after its realisation. Our exploration was limited to an analysis of swallowing duration, bolus fragmentation and of temporal coordination between swallowing and breathing. The method used an association of non invasive validated methods previously published for which normal values were available [12, 14, 39] and which do not influence the physiological condition (no mask, no nasal obstruction, no anesthesia, no pain, and possibility to use the preferred position). On the basis of these first paradoxical results (improvement of swallowing parameters with tracheostomy), it appears now useful to confirm these results with additional techniques and to test swallowing ability with semisolid consistencies.

correction d'Hélène (sur la macroglossie) à rajouter ici. 


\section{CONCLUSION}

The main clinical implication of our study findings is that tracheostomy combined with positive pressure ventilation may deserve consideration as a mean to improve swallowing duration and fragmentation in DMD patients who are dependent on the ventilator. There is no consensus about the optimal time for performing percutaneous endoscopic gastrostomy relative to tracheostomy [6]. Because the ability to eat improves perceived quality of life, one approach could be to perform tracheostomy first when it is decided for ineffective NIV and to assess its effects on swallowing before making a decision about a gastrostomy. Further clinical studies are needed to evaluate the impact of invasive mechanical ventilation throughout an entire meal and to confirm our suggestion that tracheostomy may delay the need for gastrostomy. 


\section{Author's Contribution and Disclosure:}

NT, DO, HP and FL conceived the original protocol, initiated and executed the study. ML, LF recorded data. NT analyzed data and drafted the manuscript. DA, HP, DO, DA and FL assisted in executing the study and drafting the final manuscript. DO and FL participated in the coordination of the study. All authors read and approved the final manuscript.

All the authors report no disclosure.

Dr. Nicolas TERZI received a grant from the SRLF-SPLF (Société de Réanimation de Langue Française - Société de Pneumologie de Langue Française). The study was supported by the ADEP (Association d'Entraide des Polios et Handicapés). 


\section{REFERENCES}

[1] Eagle M., S. V. Baudouin, C. Chandler, D. R. Giddings, R. Bullock,K. Bushby. Survival in Duchenne muscular dystrophy: improvements in life expectancy since 1967 and the impact of home nocturnal ventilation. Neuromuscul Disord; 12: 926-9.

[2] Jeppesen J., A. Green, B. F. Steffensen,J. Rahbek. The Duchenne muscular dystrophy population in Denmark, 1977-2001: prevalence, incidence and survival in relation to the introduction of ventilator use. Neuromuscul Disord; 13: 804-12.

[3] Kohler M., C. F. Clarenbach, C. Bahler, T. Brack, E. W. Russi,K. E. Bloch. Disability and survival in Duchenne muscular dystrophy. J Neurol Neurosurg Psychiatry; 80: 320-5.

[4] Toussaint M., M. Steens, G. Wasteels,P. Soudon. Diurnal ventilation via mouthpiece: survival in end-stage Duchenne patients. Eur Respir J; 28: 549-55.

[5] Chailleux E., B. Fauroux, F. Binet, B. Dautzenberg,J. M. Polu. Predictors of survival in patients receiving domiciliary oxygen therapy or mechanical ventilation. A 10-year analysis of ANTADIR Observatory. Chest; 109: 741-9.

[6] Ambrosino N., N. Carpene,M. Gherardi. Chronic respiratory care for neuromuscular diseases in adults. Eur Respir J; 34: 444-51.

[7] Barbe F., M. A. Quera-Salva, C. McCann, et al. Sleep-related respiratory disturbances in patients with Duchenne muscular dystrophy. Eur Respir J; 7: 1403-8.

[8] Finder J. D., D. Birnkrant, J. Carl, et al. Respiratory care of the patient with Duchenne muscular dystrophy: ATS consensus statement. Am J Respir Crit Care Med; 170: 456-65.

[9] Pane M., I. Vasta, S. Messina, et al. Feeding problems and weight gain in Duchenne muscular dystrophy. Eur J Paediatr Neurol; 10: 231-6.

[10] Hill M., T. Hughes,C. Milford. Treatment for swallowing difficulties (dysphagia) in chronic muscle disease. Cochrane Database Syst Rev; CD004303.

[11] Willig T. N., J. R. Bach, V. Venance,J. Navarro. Nutritional rehabilitation in neuromuscular disorders. Semin Neurol; 15: 18-23.

[12] Terzi N., D. Orlikowski, P. Aegerter, et al. Breathing-swallowing interaction in neuromuscular patients: a physiological evaluation. Am J Respir Crit Care Med; 175: 269-76.

[13] Cohn M. A., A. S. Rao, M. Broudy, et al. The respiratory inductive plethysmograph: a new non-invasive monitor of respiration. Bull Eur Physiopathol Respir; 18: 643-58.

[14] Ertekin C., M. Pehlivan, I. Aydogdu, et al. An electrophysiological investigation of deglutition in man. Muscle Nerve; 18: 1177-86. 
[15] Aloysius A., P. Born, M. Kinali, T. Davis, M. Pane,E. Mercuri. Swallowing difficulties in Duchenne muscular dystrophy: indications for feeding assessment and outcome of videofluroscopic swallow studies. Eur J Paediatr Neurol; 12: 239-45.

[16] Borg G. A. Psychophysical bases of perceived exertion. Med Sci Sports Exerc; 14: $377-81$.

[17] Nishino T., T. Yonezawa,Y. Honda. Effects of swallowing on the pattern of continuous respiration in human adults. Am Rev Respir Dis; 132: 1219-22.

[18] Smith J., N. Wolkove, A. Colacone,H. Kreisman. Coordination of eating, drinking and breathing in adults. Chest; 96: 578-82.

[19] Paydarfar D., R. J. Gilbert, C. S. Poppel,P. F. Nassab. Respiratory phase resetting and airflow changes induced by swallowing in humans. J Physiol; 483 ( Pt 1): 273-88.

[20] Hauser S. L., D. M. Dawson, J. R. Lehrich, et al. Intensive immunosuppression in progressive multiple sclerosis. A randomized, three-arm study of high-dose intravenous cyclophosphamide, plasma exchange, and ACTH. N Engl J Med; 308: 173-80.

[21] Make B. J., N. S. Hill, A. I. Goldberg, et al. Mechanical ventilation beyond the intensive care unit. Report of a consensus conference of the American College of Chest Physicians. Chest; 113: 289S-344S.

[22] Clinical indications for noninvasive positive pressure ventilation in chronic respiratory failure due to restrictive lung disease, COPD, and nocturnal hypoventilation--a consensus conference report. Consensus Conference Report; 116: 521-34.

[23] Shaker R., Q. Li, J. Ren, et al. Coordination of deglutition and phases of respiration: effect of aging, tachypnea, bolus volume, and chronic obstructive pulmonary disease. Am J Physiol; 263: G750-5.

[24] Gross R. D., C. W. Atwood, Jr., S. B. Ross, J. W. Olszewski,K. A. Eichhorn. The coordination of breathing and swallowing in chronic obstructive pulmonary disease. Am $\mathbf{J}$ Respir Crit Care Med; 179: 559-65.

[25] Kijima M., S. Isono,T. Nishino. Coordination of swallowing and phases of respiration during added respiratory loads in awake subjects. Am J Respir Crit Care Med; 159: 1898-902. [26] Misuri G., B. Lanini, F. Gigliotti, et al. Mechanism of $\mathrm{CO}(2)$ retention in patients with neuromuscular disease. Chest; 117: 447-53.

[27] Nishino T., R. Hasegawa, T. Ide,S. Isono. Hypercapnia enhances the development of coughing during continuous infusion of water into the pharynx. Am J Respir Crit Care Med; 157: $815-21$. 
[28] Gross R. D., C. W. Atwood, Jr., J. P. Grayhack,S. Shaiman. Lung volume effects on pharyngeal swallowing physiology. J Appl Physiol; 95: 2211-7.

[29] Tolep K., C. L. Getch,G. J. Criner. Swallowing dysfunction in patients receiving prolonged mechanical ventilation. Chest; 109: 167-72.

[30] Dettelbach M. A., R. D. Gross, J. Mahlmann,D. E. Eibling. Effect of the Passy-Muir Valve on aspiration in patients with tracheostomy. Head Neck; 17: 297-302.

[31] Elpern E. H., M. Borkgren Okonek, M. Bacon, C. Gerstung,M. Skrzynski. Effect of the Passy-Muir tracheostomy speaking valve on pulmonary aspiration in adults. Heart Lung; 29: 287-93.

[32] Stachler R. J., S. L. Hamlet, J. Choi,S. Fleming. Scintigraphic quantification of aspiration reduction with the Passy-Muir valve. Laryngoscope; 106: 231-4.

[33] Suiter D. M., G. H. McCullough,P. W. Powell. Effects of cuff deflation and one-way tracheostomy speaking valve placement on swallow physiology. Dysphagia; 18: 284-92.

[34] Leder S. B. Effect of a one-way tracheotomy speaking valve on the incidence of aspiration in previously aspirating patients with tracheotomy. Dysphagia; 14: 73-7.

[35] Toussaint M., M. Steens,P. Soudon. Lung function accurately predicts hypercapnia in patients with Duchenne muscular dystrophy. Chest; 131: 368-75.

[36] Martin B. J., J. A. Logemann, R. Shaker,W. J. Dodds. Coordination between respiration and swallowing: respiratory phase relationships and temporal integration. $\mathbf{J}$ Appl Physiol; 76: 714-23.

[37] Hadjikoutis S., T. P. Pickersgill, K. Dawson,C. M. Wiles. Abnormal patterns of breathing during swallowing in neurological disorders. Brain; 123 ( Pt 9): 1863-73.

[38] Langmore S. E., K. Schatz,N. Olsen. Fiberoptic endoscopic examination of swallowing safety: a new procedure. Dysphagia; 2: 216-9.

[39] Ertekin C., N. Yuceyar, Aydogdu,H. Karasoy. Electrophysiological evaluation of oropharyngeal swallowing in myotonic dystrophy. J Neurol Neurosurg Psychiatry; 70: 36371. 


\section{Figure Legends}

Figure 1: Swallowing time (Panel A) and number of swallows (Panel B) per bolus according to bolus size $(5,10$, or $15 \mathrm{ml})$ and test condition $((\triangle)$ before and $(\boldsymbol{\nabla})$ after tracheostomy).

Figure 2: Individual values for 15-ml bolus data: swallowing time (panel A) and number of swallows (panel B) before and after tracheostomy. Two patients (arrows) were unable to swallow $15 \mathrm{ml}$ before tracheostomy, whereas all patients could swallow all bolus sizes after tracheostomy. 